\title{
PERANCANGAN CASE TOOLS \\ UNTUK DIAGRAM USE CASE, ACTIVITY, DAN CLASS UNTUK PERMODELAN UML BERBASIS WEB MENGGUNAKAN HTML5 DAN PHP
}

\author{
Mohammad Subekti; Lukman; Donny Indrawan; Ganesh Putra \\ Computer Science Department, School of Computer Science, Binus University \\ Jl. K.H. Syahdan No. 9, Palmerah, Jakarta Barat 11480 \\ subekti@binus.ac.id
}

\begin{abstract}
This study is intended to generate an application tools (CASE tools) that allows a software developer to create a modeling system design using Unified Modeling Language (UML), especially in making use case, activity or class diagrams more quickly and easily. The tools developed will also facilitate developers in doing UML modeling by accessing the network through a web-based internet application. With the web-based applications, the users require only a browser and an internet connection to use this application. This application also helps developers to understand of how to make UML diagrams correctly and good. In this research traditional methods Scrum model is used. Scrum method is Agile methods that is a process to cultivate software easily and can be developed in accordance with the development of information technology. Scrum is using empirical methods or in other words every stage in it involves inspection and adaptation.
\end{abstract}

Keywords: scrum method, agile method, case tools, UML diagram, use case diagram, activitydiagram, classdiagram

\begin{abstract}
ABSTRAK
Penelitian ini adalah dimaksudkan untuk membuat sebuah aplikasi alat bantu (CASE tool) yang memungkinkan seorang pengembang dapat membuat rancangan sistem dengan permodelan Unified Modeling Language (UML) khususnya dalam membuat diagram-diagram use case, activity atau class dengan lebih cepat dan mudah. Alat bantu yang dikembangkan, juga dapat mempermudah pengembang dalam melakukan pengaksesan dan pembuatan model UML melalui jaringan internet karena dibuat berbasiskan web. Dengan berbasiskan web, maka untuk menjalankan aplikasi ini pengguna hanya memerlukan perangkat lunak browser dan koneksi internet. Aplikasi ini juga membantu pengembang untuk memahami pembuatan diagram UML yang benar dan baik. Penelitian yang dilakukan tim penulis menggunakan metode Scrum Model. Metode Scrum, adalah metode Agile yang merupakan proses untuk mengolah perangkat lunak dengan mudah serta dapat dikembangkan sesuai dengan perkembangan teknologi informasi. Scrum menggunakan metode empiris atau dengan kata lain setiap tahap di dalamnya melibatkan inspeksi dan adaptasi.
\end{abstract}

Kata kunci: metoda scrum, metoda agile, CASE tools, UML, diagram Use Case, diagram activity, diagram class 


\section{PENDAHULUAN}

Saat ini berbagai piranti lunak semakin luas penggunaannya, baik untuk sistem yang sederhana maupun untuk sistem yang kompleks. Piranti lunak diharapkan menghasilkan luaran yang baik, sehingga perlu dibuat dengan menggunakan pemodelan (modeling) yang sebaik mungkin dan memerlukan penanganan yang jelas jika terjadi error atau bug.

Pemodelan (modeling) adalah proses merancang piranti lunak sebelum melakukan pengkodean (coding). Model piranti lunak dapat dianalogikan seperti pembuatan blueprint pada pembangunan gedung. Membuat model dari sebuah sistem yang kompleks sangatlah penting karena untuk memahami sistem yang kompleks secara menyeluruh sangat sulit. Semakin kompleks sebuah sistem, semakin penting pula penggunaan teknik pemodelan yang baik. Kesuksesan suatu pemodelan piranti lunak ditentukan oleh tiga unsur, yang kemudian terkenal dengan sebutan segitiga sukses (the triangle for success). Ketiga unsur tersebut adalah metode pemodelan (notation), proses (process) dan tool yang digunakan.

CASE tools merupakan teknik yang digunakan untuk membantu melakukan beberapa fase, yakni fase analisis, desain, maintenance, dan implementsi dalam perancangan piranti lunak. Dengan menggunakan CASE tools maka dapat memperbesar kemungkinan otomatisasi pada setiap fase lifecycle piranti lunak dan sangat membantu dalam meningkatkan kualitas rancangan model suatu piranti lunak sebelum piranti lunak itu dibangun/dikembangkan, baik piranti lunak yang dibangun dalam environment yang sederhana maupun kompleks. Kebanyakan CASE tools yang digunakan berbasis desktop sehingga memerlukan instalasi yang cukup panjang pada setiap komputer yang ingin digunakan, terbatas pada sistem operasi tertentu, media yang terbatas untuk mengakses aplikasi tersebut, dan memerlukan spesifikasi komputer yang tinggi untuk menjalankan aplikasi.

Melihat kelemahan-kelemahan pada aplikasi CASE tools berbasis desktop, maka penulis merancang aplikasi CASE tools berbasis Web. Dengan CASE tools berbasis Web, maka masalahmasalah tersebut di atas dapat diselesaikan dan perancangan piranti lunak dapat dibuat secara lebih efisien. Aplikasi berbasis Web dapat dijalankan tanpa instalasi piranti lunak khusus untuk menggunakannya, melainkan hanya memerlukan browser dan akses internet. CASE tools berbasis Web dapat digunakan di mana saja dan kapan saja, dijalankan pada sistem operasi apa saja, dan diakses melalui banyak media seperti handphone dan komputer yang sudah sesuai dengan standar WAP, serta tidak memerlukan spesifikasi tinggi untuk menggunakan aplikasi berbasis Web ini karena sebagian besar proses dilakukan di website server penyedia aplikasi.

Melihat kebutuhan dan teknologi yang ada, maka dibutuhkan aplikasi CASE tools untuk pemodelan UML yang handal dan mempunyai fungsionalitas standar UML dengan menggunakan HTML5 yang memiliki integrasi yang lebih baik. Adapun fitur yang akan dibuat adalah Save dan Open Project secara online pada website, dan Mulptiple Diagram in one Project.

Penelitian dimaksudkan untuk menjawab berbagai permasalahan dalam proses pengembangan aplikasi sistem informasi modern, antara lain: Aplikasi berbasis web seperti apa yang dapat mempercepat pembuatan pemodelan UML secara efektif dan efisien? Bagaimana aplikasi berbasis web ini dapat menyimpan hasil pemodelan UML lebih baik dibanding aplikasi desktop? Bagaimana aplikasi berbasis web ini dapat menghubungkan satu diagram dengan diagram lain pada saat dijalankan di browser? Bagaimana aplikasi berbasis Web ini dapat dijalankan lebih ringan dari pada aplikasi desktop?

Dari berbagai pertanyaan tersebut dapat diformulasikan kemungkinan sebuah rancangan alat bantu untuk pengembangan perangkat lunak yang mempunyai karakteristik-karakteristik sebagai berikut, yaitu: sebuah aplikasi alat bantu pembuatan model UML berbasis Web, yang lebih efisien dan efektif dibandingkan dengan aplikasi desktop yang sekarang ini ada. Alat bantu harus memiliki fitur 
Save dan Open Projectsecara online di jaringan internet yang memungkinkan pengembang menyimpan hasil pembuatan pemodelan UML tersebut berdasarkan lokasi objek diagram yang dibuat, sehingga pada saat dibuka kembali project tersebut dapat ditampilkan kembali pada web browser seperti yang telah penulis buat sebelumnya. Alta bantu juga harus memiliki fitur Drag and Drop di dalam browser untuk memudahkan pembuatan UML hanya dengan melakukan drag and drop seperti halnya pada desktop. Yang terakhir, alat ini harus memiliki fitur Mulptiple Diagram in one Project memungkinkan user membuat banyak jenis diagram UML dalam satu project.

Penelitian ini ditujukan untuk menghasilkan CASE tool UML yang dijalankan secara online yang memungkinkan untuk bekerja lebih cepat dan efisien. Bagi user, dapat mempermudah pembuatan pemodelan UML karena hanya memerlukan browser dan koneksi internet maka CASE tool dapat langsung digunakan.Perancangan aplikasi ini dibatasi pada pembuatan model data konseptual dan model data fisik dari UML, antara lain: class diagram, use case diagram, dan activity diagram. Aplikasi ini menyediakan fasilitas online save karena berbasiskan website sehingga user dapat mengakses UML nya di mana saja dan user lain pun dapat mengaksesnya.

\section{METODE}

Metode penelitian yang digunakan adalah permodelan Scrum (Sutherland, 2010) yang merupakan salah satu jenis Agile Piranti lunak Development Method. Menurut Cervone (2011), Scrum adalah Agile itu sendiri yang merupakan proses yang ringan untuk mengelola dan mengendalikan pengembangan piranti lunak dan produk dalam lingkungan yang berubah dengan cepat. Pada permodelan Scrum ada roles/peran, artifacts dan process yang penting untuk dipahami.

Scrum Roles terdiri dari: Scrum Master, peran dari Scrum Master adalah membantu Scrum Team supaya memberikan performa terbaik dan mengatasi hambatan yang dihadapi dalam proses pengerjaan. Scrum Master tidak menentukan tugas Scrum Team, melainkan fokus kepada team dan tantangan yang dihadapi. Scrum Team merupakan tim yang bekerja secara mandiri dan menentukan tugas-tugas yang akan diselesaikan di dalam sprint. Product Owner adalah stakeholders yang tahu apa yang harus dibangun dan bagaimana seharusnya progress berjalan.

Sedangkan Scrum Artifacts adalah terdiri atas: Product backlog merupakan daftar kebutuhan backlog items, yaitu fitur dan produk yang akan diselesaikan dan diatur berdasarkan skala prioritas. Sprint backlog merupakan daftar tahap pengerjaan untuk penyelesaian backlog items yang dibuat secara mandiri oleh Scrum Team. Burn down charts adalah diagram yang digunakan untuk mengindikasikan progress dari keseluruhan project.

Berikut adalah proses kerja dalam Scrum Process: (1) Kickoff Meeting adalah pertemuan yang dihadiri oleh Scrum Master, Scrum Team, dan Product Owner untuk menentukan tujuan utama proyek. (2) Sprint Planning adalah meeting yang dihadiri oleh Scrum Master, Scrum Team, dan Product Owner diawal setiap iterasi(sprint). Fokus meeting ini ada dua hal yaitu: pertama menentukan product backlog dan hasil akhir sprint. Kedua, menentukan sprint backlog. (3) Sprint merupakan proses pengerjaan product backlog sesuai dengan sprint backlog yang dilakukan oleh Scrum Team. Dalam proses pengerjaan akan berjalan secara tertutup dan tidak boleh ada perubahan requirements. (3) Daily Scrum adalah pertemuan singkat sepenulisr 15 menit yang dipimpin oleh Scrum Mastersebelum memulai sprint setiap harinya. Pertanyaan yang biasa ditanyakan pada pertemuan ini antar: Apa yang sudah dilakukan pada Scrum terakhir? Apa yang akan kalian lakukan untuk Scrum berikutnya? Apa yang membuat pekerjaan kalian tertunda? Tujuan dari pertemuan singkat ini adalah melacak progress dari sprint dan membentuk komitmen yang kuat antar anggota tim. (4) Sprint Review Meeting dilaksanakan pada akhir sprint dan mendemonstrasikan hasil sprint kepada Product Owner. 


\section{Tinjauan Pustaka}

Pada umumnya CASE tools dijalankan dengan berbasis desktop, dan tidak dapat diakses di website. CASE tool berbasis Web merupakan alat yang dapat membantu mengatasi masalah ini karena memberikan pengembangan yang didistribusikan secara geografis sehingga pengembang dapat berkolaborasi dan bekerja sama dalam proyek piranti lunak secara lebih efisien. (Palaniappan, Ling, 2008).

Banyak tools UML yang sudah ada saat ini terlalu berat untuk menghasilkan model yang sederhana dengan cepat. Tools UML seperti ini biasanya mengandung banyak fungsionalitas, yang dapat menyebabkan masalah kegunaan dan produktivitas yang kurang. Tools UML yang ringan dirancang untuk mendukung pembuatan model yang cepat dan mudah. Penggunaan website telah meningkatkan manfaat dalam pembuatan model termasuk portabilitas dan kolaborasi penggunaan. (Mackay, Noble, Biddle, 2002).

Pendekatan tradisional untuk menyediakan tools diagram seperti CASE tools, CAD tools dan tools desain antarmuka adalah program yang menggunakan teknologi thick client, di mana program dapat dijalankan pada komputer host dan menggunakan fasilitas desktop grafis. Keunggulan utamanya adalah interaksi yang sangat responsif ketika langsung memanipulasi diagram dan kemampuan alat pengembang untuk menggunakan semua fasilitas grafis yang tersedia pada komputer host. Namun, tools diagram yang masih tradisional memiliki masalah umum, antara lain aplikasi perlu di-install dan secara berkala diperbaharui di semua komputer host, user interface yang kompleks, dan membutuhkan infrastruktur yang cukup kompleks untuk mendukung multi-user kolaboratif, terutama sinkronisasipembuatan diagram. (Cao et al, 2005).

Dengan melihat berbagai pendekatan dari jurnal serta permasalahan yang ada, maka perlu dibuat sebuah aplikasi CASE tools berbasis Web dengan menggunakan HTML 5 sebagai aplikasi yang handal, ringan, serta mudah digunakan dan memiliki user interface yang friendly untuk dapat memudahkan user dan system analyst yang hendak membuat pemodelan UML dengan menggunakan CASE tools yang memiliki banyak kelebihan.

\section{HASIL DAN PEMBAHASAN}

\section{Analisis Aplikasi}

Untuk analisis aplikasi ini, penulis mengumpulkan informasi dengan membandingkan jurnaljurnal penelitian ilmiah yang berkaitan dengan topik Case Tools berbasis Web, dalam sub-bab ini akan dijelaskan tentang permasalahan yang dihadapi peneliti sebelumnya terkait dengan perancangan aplikasi sejenis. Penulis mengambil tiga penelitian yang paling mendekati dengan topik perancangan Case Tools berbasis web sebagai berikut: (1) Alatbantu pengembangan perangkat lunak CASE Berbasis Web untuk Automated Rendering UML. (2) Menggunakan antar muka pengguna berbasis Web User untuk penggambaran Diagram Model. (3) Alat bantu pengembangan ringan (light weight) untuk diagram UML dijalankan di semua jenis platform.

Pada penelitian sebelumnya, Palaniappan (2008) memaparkan tujuan dari perancangan Case Tools berbasis Web adalah menghasilkan aplikasi yang dapat langsung menghasilkan secara otomatis diagram sesuai dengan urutan atau tata letak diagram dan mempunyai fitur web-enabled serta tidak memerlukan instalasi. Dengan adanya sistem render otomatis model UML, memungkinkan setiap anggota tim atau user dapat melihat hasil kerja anggota tim lainnya atau user lainnya sehingga mereka dapat bekerja sama dalam proyek software yang sama di tempat yang berbeda. Penelitian ini juga menjelaskan setiap diagram harus memberikan posisi triplet atau koordinat yang dinamis dan interaktif. 
Penelitian kedua menurut (Cao et al, 2005) menjelaskan dalam penelitiannya, aplikasi Case Tools yang dirancang adalah desktop aplikasi yang dilengkapi dengan fitur website editing, dalam aplikasi tersebut ditambahkan fitur baru di mana user dapat melakukan pembuatan dan editing diagram UML melalui website yang terhubung dengan aplikasi desktop tersebut. Untuk menghubungkan kedua aplikasi digunakan interpreter meta-tools yang menyediakan server aplikasi bersama yang didukung menggunakan arsitektur web.

Penelitian ketiga menurut (Mackay, Noble, Biddle, 2002), tujuan perancangan Case Tools berbasis web adalah menghasilkan sebuah aplikasi Case Tools yang ringan serta mudah dalam pembuatan model berbasiskan web. Dengan cara ini, user tidak perlu menginstal plug-ins untuk membuat UML diagram serta didukung dengan portabilitas dan group collaboration. Jika aplikasi diakses melalui browser maka tidak memerlukan ekstension khusus untuk dapat mengakses aplikasi. Tool UML yang digunakan dulu disebut sebagai heavyweight tools, di mana tools ini tidak berbasiskan web sehingga saat mengelolah data diagram, sistem tools ini membaca satu per satu data yang mengakibatkan tools tersebut berjalan lama.

Dari berbagai penelitian di atas penulis menemukan masalah yang paling banyak ditemukan dalam perancangan Case Tools adalah bagaimana membuat aplikasi yang ringan dan dapat mendukung fungsi-fungsi untuk me-render otomatis serta editing dalam diagram UML seperti desktop aplikasi dengan didukung fitur collaborative.

\section{Rangkuman Analisis}

Berdasarkan analisis berbagai penelitian sebelumnya, maka aplikasi CASE Tools berbasis Web ini seharusnya dirancang dengan memiliki fitur-fitur sebagai berikut: (1) Create New Project: fitur untuk membuat project baru sebagai tempat menyimpan hasil diagram UML. (2) Create New Canvas: fitur untuk membuat canvas sebagai tempat untuk meletakan diagram yang telah penulis buat. (3) Create Model: fitur untuk memilih model diagram UML yang akan dibuat yang terdiri dari class diagram, activity diagram, dan use case diagram. (4) Open Project: fitur untuk membuka kembali pekerjaan user yang telah dibuat pada aplikasi ini. (5) Save Project: fitur untuk menyimpan semua pekerjaan user dalam aplikasi. (6) Create Class Diagram: fitur untuk membuat class diagram beserta konektor yang terdiri dari generalisasi, agregasi, komposisi, dan asosiasi. (7) Create Activity Diagram: fitur untuk membuat activity diagram dan komponennya seperti initial dan final node, decision, fork/join, serta konektor yang terdiri dari generalisasi, agregasi, komposisi, dan asosiasi. (8) Create Use Case Diagram: fitur untuk membuat use case diagram dan komponennya seperti actor, use case, dan boundary serta konektor asosiasi. (9) Add Relation Use Case: fitur untuk membuat hubungan atau relasi untuk diagram use case berupa konektor diagram asosiasi. (10) Add Circle Use Case: fitur untuk membuat circle atau lingkaran yang merupakan bagian dari use case diagram. (11) Add Attribute Class: fitur untuk membuat dan menambahkan attribute pada class diagram. (12) Add Operation Class: fitur untuk membuat dan menambahkan operation pada class diagram. (13) Add Relation Class: fitur untuk membuat hubungan atau relasi pada class digram dalam bentuk konektor diagram generalisasi, agregasi, komposisi, dan asosiasi. (14) Add New Item Activity: fitur untuk membuat item untuk activity diagram yang menjelaskan aktivitas diagram tersebut yang menggambarkan aktivitas dari proyek. (15) Add Relationship Activity: membuat hubungan atau relasi untuk activity diagram dalam bentuk konektor diagram generalisasi, agregasi, komposisi, dan asosiasi.

\section{Analisis Aplikasi Sejenis}

Pada bagian ini akan dijelaskan hasil analisis penulis tentang perbandingan dengan aplikasi sejenis yang sudah ada dengan yang penulis buat. Penulis mengambil tiga contoh aplikasi berbasis desktop sebagai pembanding. Karena aplikasi CASE Tools berbasis web jarang ditemui, penulis 
memakai aplikasi desktop sebagai acuan untuk membuat CASE Tools dengan fitur yang lengkap dan baik. Salah satu produk yang sangat terkenal adalah IBM Rational Software Architect.

IBM Rational Software Architect adalah salah satu dari aplikasi CASE Tools berbasis desktop yang digunakan untuk memodelkan UML, mendokumentasi, serta mengelompokkan fase perancangan perangkat lunak berorientasi objek.

Kelebihan IBM Rational Software Architect antara lain: (1) Memiliki fitur yang lengkap seperti business modeling dan analisis, data modeling, reporting. (2) Dapat membuat dokumentasi dalam bentuk reporting. (3) Mendukung fitur collaboration yang mendukung untuk membuat multiple diagram dalam satu project. (4) Mendukung pemodelan database.

Sedangkan kelemahan yang dimiliki oleh IBM Rational Software Architect antara lain: (1) Kompleks untuk digunakan oleh user awam, pada umumnya aplikasi ini digunakan oleh user yang sudah berpengalaman dalam membuat pemodelan software. (2) Fitur terlalu banyak sehingga membuat user bingung untuk menemukan fitur yang diinginkan. (3) Memerlukan spesifikasi khusus yang harus dipenuhi untuk meng-install aplikasi software ini.

\section{Hasil Rancangan}

Berdasarkan analisis di atas dapat ditentukan kriteria yang akan menjadi dasar pengamatan terhadap aplikasi tersebut, seperti fitur Bussiness Modeling, Save Project, Multiple Diagram, Data Modeling, Installation Needed, Easy User Interface, dan Web Supporting. Dari aplikasi tersebut memiliki kesamaan fitur yaitu Installation Needed.

Instalasi yang dimaksud merupakan hal yang sangat penting karena jika ingin menggunakan aplikasi tersebut maka diwajibkan menginstal aplikasi tersebut pada PC atau perangkat pengguna. Tidak semua instalasi software atau aplikasi dapat dilakukan pada semua PC ataupun peringkat, karena untuk melakukan instalasi diperlukan spesifikasi minimum dan dibutuhkan platform tertentu supaya proses instalasi dapat berjalan dengan lancar. Jika spesifikasi minimum dan platform tidak terpenuhi, proses instalasi tidak akan dapat dilakukan sehingga user tidak dapat memakai perangkat lunak atau aplikasi tersebut.

Berdasarkan hasil analisis di atas, maka akan dibuat aplikasi berbasis Web sehingga tidak memerlukan installasi dan dapat langsung digunakan hanya dengan mengakses website serta tidak memerlukan spesifikasi minimum dan dapat berjalan pada semua platform. Aplikasi yang dirancang memiliki fitur-fitur, antara lain: (1) Save Project: fitur ini akan menyimpan semua hasil pekerjaan user dalam sebuah project, dan ketika user ingin membuka project-nya kembali maka aplikasi ini akan mereload project tersebut dan akan menampilkan state terakhir user saat menyimpan pekerjaannya. (2) Multiple Diagram: fitur ini akan memudahkan user untuk membuat berbagai jenis diagram dalam satu project. (3) Web Supporting: Dengan fitur ini aplikasi tersebut tidak akan memerlukan instalasi apapun sehingga user dapat langsung mengakses dan menggunakan aplikasi, karena aplikasi ini dirancang agar dapat berjalan pada basis website. (4) Easy User Interface: Fitur yang memudahkan user dalam menggunakan aplikasi, tampilan atau interface akan dirancang sedemikian rupa agar user tidak bingung dalam menggunakan aplikasi.

\section{Rancangan Aplikasi}

\section{Aplikasi CASE Tools: Diagram Use Case}

Aplikasi terdiri dari tiga bagian utama antara lain New Project berfungsi untuk mengarahkan pengembang agar dapat membuat project baru pada aplikasi, akan muncul sebuah jendela baru untuk user meng-input nama project dan direktori tempat penyimpanannya, setelah user meng-create project 
maka user akan diarahkan ke layar Case Tools UML dimana user dapat mengedit dan menambahkan diagram. Open Project berfungsi untuk membuka project yang sudah ada, dan aplikasi akan mereload dan menampilkan kembali pekerjaan user pada saat terakhir kali save. Collaboration berfungsi agar pengembang dapat bekerja dalam satu project yang sama dengan pengembang lain, pengembang dapat saling menambahkan dan mengurangi diagram dalam pekerjaan mereka dan aplikasi akan memutakhirkan secara langsung tanpa perlu me-refresh halaman website.

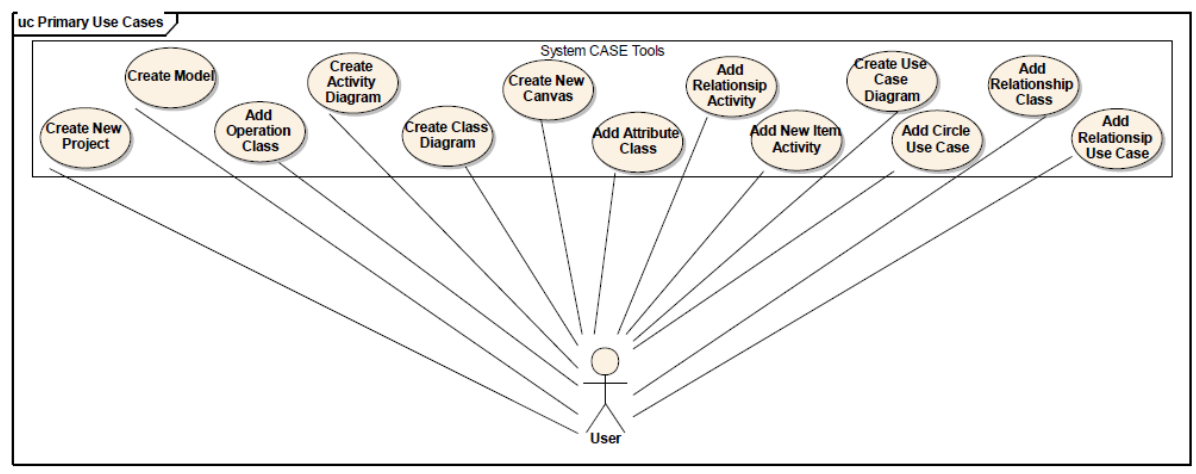

Gambar 1 Diagram Use Case Aplikasi CASE Tools

Rancangan aplikasi Case Tools adalah dimulai dengan menampilkan halaman web di mana pengembang dapat mengedit dan menambahkan diagram UML pada proyek yang sedang dikerjakan. Desain layar Case Tools terdiri dari lima bagian yaitu menu yang berfungsi agar pengembang dapat membuat proyek baru, membuka proyek yang sudah ada, serta dapat menyimpan proyek yang telah dibuat. Bagian menu ini akan membantu pengembang untuk men-setting tampilan layar Case Tools. Project akan menampilkan semua pekerjaan pengembang berupa folder project dan diagram beserta nama project dan nama diagram lalu menampilkannya dalam bentuk treemenu. Pallete berisi tipe diagram yang disediakan oleh aplikasi dan pengguna dapat menggunakannya dengan men-drag ke dalam canvas. Properties menampilkan attribute yang terdapat pada diagram. Canvas adalah tempat semua diagram yang dibuat oleh user diletakkan.

Create New Project berfungsi agar user dapat membuat project baru, setiap ingin membuat project baru maka akan muncul jendela baru yang akan meminta user untuk meng-input nama project dan menentukan ekstensi untuk menyimpan project tersebut. Setelah selesai men-input maka user dapat memulai membuat diagram dan semua project user akan ditampilkan pada bagian Project.

Create New Model berfungsi agar user memilih tipe diagram apa yang akan dibuat. Tipe diagram pada aplikasi ini terdiri dari class diagram, use case diagram, dan activity diagram. Jendela akan muncul setelah pengembang selesai meng-input nama dan direktori penyimpanan project.

Pallete Diagram berfungsi menampilkan tipe diagram dan komponen dari masing-masing tipe diagram, untuk memakai tipe diagram dan komponennya maka userharus men-drag tipe diagram tersebut ke dalam canvas yang terdapat pada bagian tengah layar Case Tools. Setelah itu aplikasi akan menampilkan diagram sesuai dengan tipe yang di-drag oleh user.

User dapat menambahkan attributes pada diagram, saat user men-drag tipe diagram dari pallete aplikasi juga akan memuculkan jendela baru agar user dapat menginput attributes ataupun operation pada diagram. Nilai dari masukan pengguna akan ditampilkan pada diagram dan juga pada bagian properties. Pengguna juga dapat mengedit nilai tersebut dengan menggantinya pada bagian properties. 
Add Diagram Type berfungsi untuk menambahkan tipe diagram baru pada project user. User dapat menambah diagram dengan meng-klik kanan pada nama project yang user buat pada bagian Project, setelah itu akan muncul pilihan untuk memilih tipe diagram. Pada bagian Project akan terupdate diagram baru dan aplikasi akan meng-create sebuah canvas baru.

Pengguna dapat meng-add conector pada diagram yang fungsinya untuk menjelaskan hubungan diagram yang satu dengan diagram lainnya. Setiap diagram memiliki connector masingmasing dengan jenis berbeda, pengguna dapat membuat connector pada diagram dengan menghubungkan kedua lingkaran kecil yang terdapat pada diagram dan menarik garis pada lingkaran tersebut untuk dihubungkan ke diagram lain. Lingkaran tersebut akan muncul jika user meng-klik pada diagram.

\section{Aplikasi CASE Tools: Diagram Class}

Untuk penyimpanan hasil permodelan adalah di dalam bentuk database. Setiap objek yang ada direpresentasikan dalam bentuk class, sebagai bentuk baru dan lebih komprehensif dari bentuk yang sebelumnya disebut entity. Rancangan dasar dari objek adalah tipe objek, yang mewakili kelompok objek dengan sifat yang sama. Sebuah tipe objek memiliki eksistensi independen terhadap keberadaan fisik benda terhadap keberadaan konseptual (atau abstraksi). Setiap objek dapat diidentifikasi secara unik dari suatu entity yang disebut hanya sebagai suatu kejadian entitas. Sebuah database biasanya berisi banyak jenis objek kelas yang berbeda. Pada Gambar 2, Gambar 3, dan gambar 4 merupakan representasi objek yang diperlukan di dalam setiap pembuatan diagram setiap aplikasi bisnis, yaitu dalam pembuatan diagram use case, diagram class, dan pembuatan diagram activity. Setiap jenis entitas ditampilkan sebagai persegi panjang diberi label dengan nama entitas, yang biasanya kata benda tunggal yang merupakan identitas dari objek bersangkutan.

Daftar kelas objek untuk mendukung aplikasi sesuai dengan gambar 2, gambar 3, dan gambar 4 dan sesuai dengan rincian penjelasan pada Tabel 1.

Tabel 1 Daftar Kelas Objek untuk mendukung Aplikasi CASE Tools

\begin{tabular}{|c|c|c|}
\hline No & Nama Kelas Objek & Atribut \\
\hline 1 & modelType & NameModelTyp e : CHAR (36), IdModelTyp e CHAR (36)* \\
\hline \multirow[t]{3}{*}{2} & general_Model & ModelName : VARCHAR (100) \\
\hline & & IdGeneralModel: CHAR (36)* \\
\hline & & IdModelType : CHAR (36)\# \\
\hline 3 & general_Canvas & CanvasName : CHAR (36), IdGeneralCanvas : CHAR (36)* \\
\hline \multirow[t]{2}{*}{4} & general_Project & ProjectName : VARCHAR (100) \\
\hline & & IdGeneralProject: CHAR (36)*, IdGeneralCanvas : CHAR (36)\# \\
\hline 5 & typeClass & $\begin{array}{l}\text { typeclassID: CHAR(36)*, typeclassName: CHAR(36), idMethod: CHAR(36)\#, } \\
\text { idAttribute: CHAR(36)\#, RelationClassID: CHAR(36)\# }\end{array}$ \\
\hline 6 & general_Class & classname: VARCHAR(100), idgeneralclass: CHAR(36)*, typeclassID: CHAR(36)\# \\
\hline 7 & attribute_class & Name: CHAR(36), idAttribute: CHAR(36)* \\
\hline 8 & general_Activity & $\begin{array}{l}\text { Activity_Name: VARCHAR(100), ID_generalA ctivity: CHAR(36)*, } \\
\text { AttributeActivityID : CHAR(36)\#, ComponentActivityID : CHAR(36)\# }\end{array}$ \\
\hline 9 & AttributeActivity & AttributeActivityName: CHA R(36), AttributeActivityID : CHAR(36)* \\
\hline 10 & MethodClass & Name: CHAR(36), idMethod: CHAR(36)* \\
\hline 11 & RelationClass & Name: CHAR(36),RelationClassID: CHAR(36)* \\
\hline 12 & componentActivity & ComponentActivityName : CHAR (36), ComponentActivityID : CHAR (36)* \\
\hline 13 & general_UseCase & $\begin{array}{l}\text { UseCase_Nam e : VARCHAR(100), ID_GeneralUseCase : CHAR(36 )*, } \\
\text { CircleUseCaseID : CHAR(36 )\#, RelationUseCaseID : CHAR(36)\# }\end{array}$ \\
\hline 14 & circle_UseCase & CircleName : CHAR(36), CircleUseCaseID : CHAR(36)* \\
\hline
\end{tabular}

Catatan: * primary key, \# foreign key 


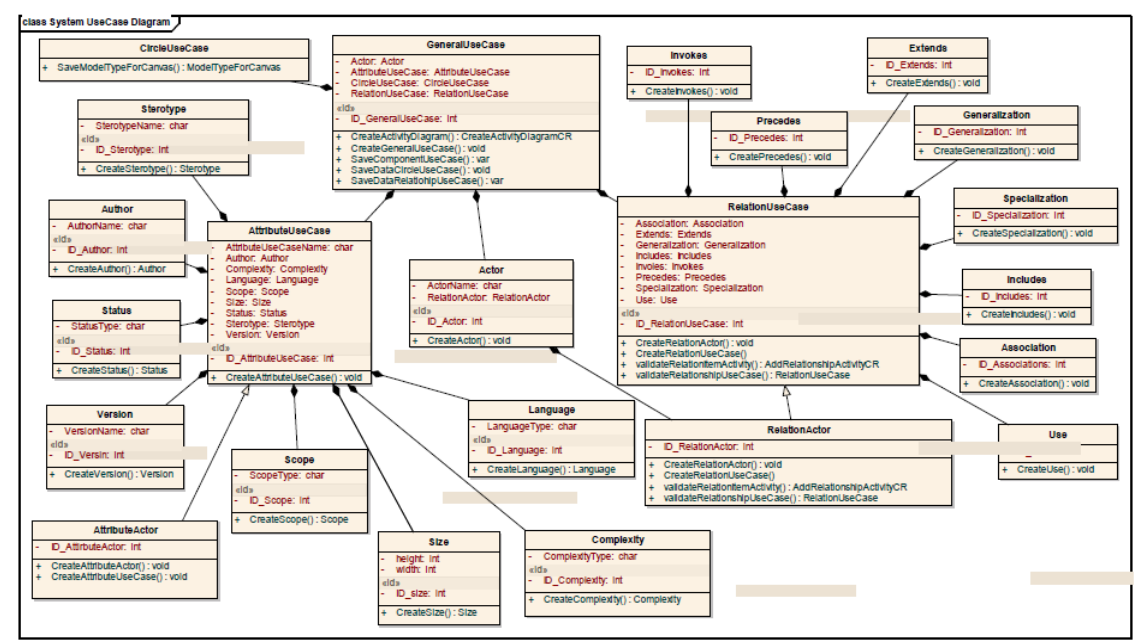

Gambar 2 Class Diagram Untuk Aplikasi Use Case Diagram

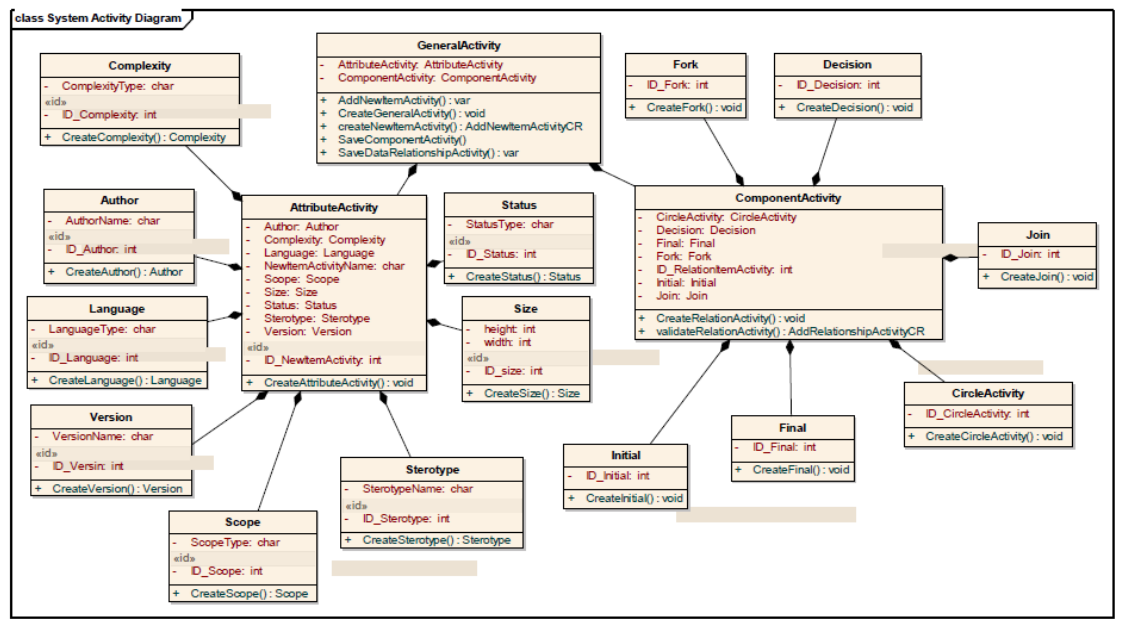

Gambar 3 Class Diagram Untuk Activity Diagram

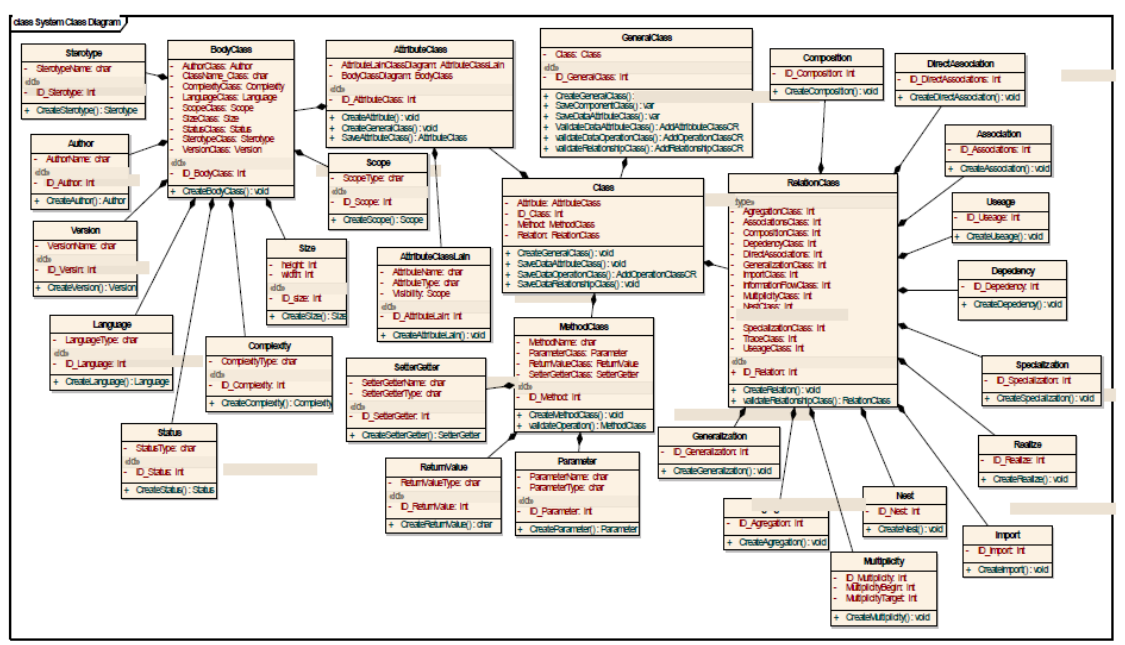

Gambar 4 Class Diagram Untuk Class Diagram 


\section{Aplikasi CASE Tools: Diagram Sequence}

Produk selanjutnya dari rancangan CASE Tools, adalah berupa diagram sequence. Model diagram sequence merepresantasikan interaksi antar objek sepanjang waktu. Dalam diagram ditunjukkan objek dan pesan yang bergerak dari suatu objek dan ke objek yang lain sesuai yang ditunjukkan dalam diagram use case. Dalam diagram sequence object dan actor ditampilkan sebagai kolom, dengan vertical lifelines menunjukkan waktu hidup pada garis waktu. Sedangkan aktivitas ditunjukkan dengan notasi kotak persegi panjang pada horizontal life lines.

Pada gambar 5, diperlihatkan salah satu diagram sequence, namun karena jumlah diagram sequence yang terlalu banyak jadi tidak bisa dimuat dalam tulisan ini. Namun terdapat dalam referensi pada artikel ini, dengan judul dan penulis yang sama.

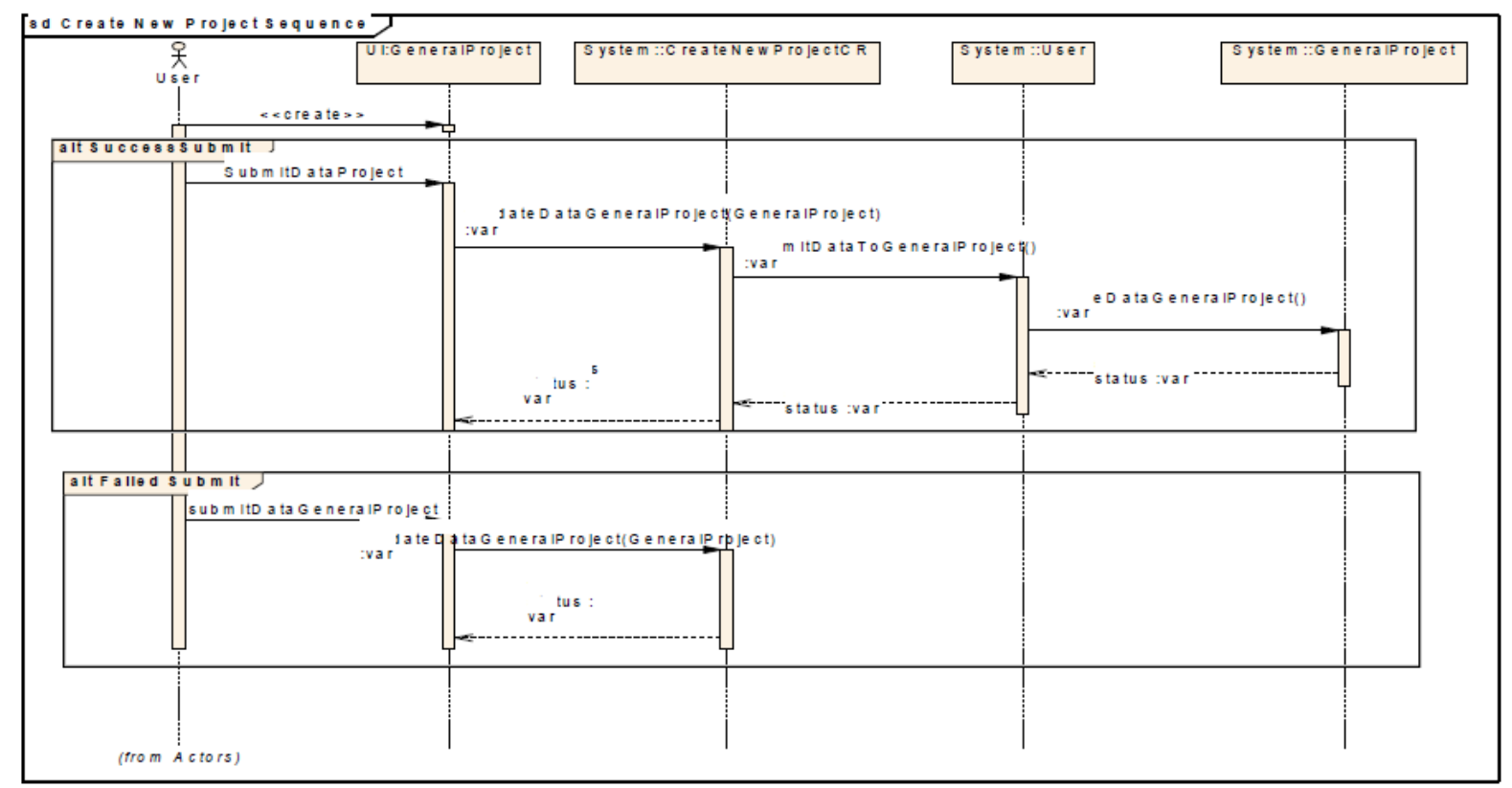

Gambar 5 Sequence Diagram dari Create New Project

\section{Hasil Evaluasi}

Pada sub-bab ini dilakukan evaluasi terhadap user dengan menggunakan kuesioner dengan tujuan untuk mengetahui apakah aplikasi dengan platform website ini lebih dibutuhkan dari pada aplikasi CASE Tools berbasis desktop pada umumnya. Target responder penulis adalah mahasiswa Bina Nusantara jurusan Teknik Informatikaangkatan 2009, alasannya karena aplikasi ini dirancang dengan tujuan agar dapat memenuhi kebutuhan standar mahasiswa dalam pembuatan permodelan diagram UML.

Pertanyaan-pertanyaan diajukan untuk mengetahui persentase pilihan responder untuk aplikasi open source atau dapat digunakan tanpa harus membayar license, karena pada umumnya aplikasi CASE Tools banyak yang berbayar atau harus menggunakan license. Hasilnya 95\% mengatakan ingin, dan 5\% lainnya tidak. Dari hasil evaluasi kuesioner terhadap responder maka dapat diketahui bahwa aplikasi CASE Tools berbasis website ini sangat dibutuhkan terutama untuk kebutuhan membuat pemodelan dengan UML yang mudah dalam penggunaan interface aplikasi dan open source, tidak memerlukan instalasi, dan memiliki fitur save project. 


\section{SIMPULAN}

Berdasarkan penelitian yang telah dilakukan maka dapat disimpulkan bahwa dari perancangan aplikasi CASE Tools berbasis Web ini yang telah dikembangkan menyangkut beberapa hal: pertama, aplikasi yang dirancang berbasis Web ini tidak memerlukan instalasi dan spesifikasi yang besar dalam menggunakan atau menjalankan aplikasi. Selanjutnya, dengan berbasis Web, maka semua data project UML yang dibuat oleh user pada aplikasi ini akan disimpan secara online, dan user dapat membuka kembali proyek tersebut. Hal ini memudahkan user dalam menyimpan dan membuka kembali semua pekerjaannya karena semua data telah disimpan pada aplikasi. Aplikasi ini dirancang dengan standarisasi tampilan interface dan fitur-fitur CASE Tools yang biasanya terdapat pada desktop aplikasi sehingga memudahkan bagi user sudah terbiasa menggunakan aplikasi CASE Tools berbasis desktop. Aplikasi ini dirancang agar dapat berjalan secara ringan dan cepat dengan fitur-fitur yang biasanya hanya terdapat aplikasi desktop. User dapat menggunakanaplikasi CASE Tools berbasis Web ini seperti menggunakan aplikasi desktop.

Berdasarkan kesimpulan di atas, yang diperoleh dengan keterbatasan yang terdapat pada perancangan aplikasi ini, maka saran yang dapat dipertimbangkan untuk pengembangan aplikasi selanjutnya adalah: (1) Pengembangan aplikasi di mana tidak hanya untuk pemodelan UML saja, tapijuga untuk pemodelan database dan proses bisnis untuk pembuatan software. (2) Menambahkan fitur online collaboration di mana sesama user dapat mengerjakan satu project secara bersamaan.

\section{DAFTAR PUSTAKA}

Cao, S., Grundy, J., Hosking, J., Stoeckle, H., Tempero, E., \& Zhu, N. (2005).Generating WebbasedUser Interfaces for Diagramming Tools. Department of Computer Science and Department of Electrical and Computer Engineering University of Auckland , 1-10.

Cervone, H. (2011). Understanding agile project management methods using Scrum. (OCLC Systems and Services.

Mackay, D., Noble, J., Biddle, R. (2002).A Lightweight Web-Based Case Toolfor UML Class Diagrams.Victoria University Of Wellington , 1-7.

Palaniappan, S., \& Ling, L. (2008).Web-Based CASE Tool for AutomatedRendering of UML. IJCSNS International Journal 146 of Computer Scienceand Network Security, 1-7.

Sutherland, J. (2010). Jeff Sutherland's Scrum Handbook.Somerville: The ScrumTraining Institute 